\title{
Waste Polystyrene Degradation in the World Oceans: Newly identified sources of Contamination
}

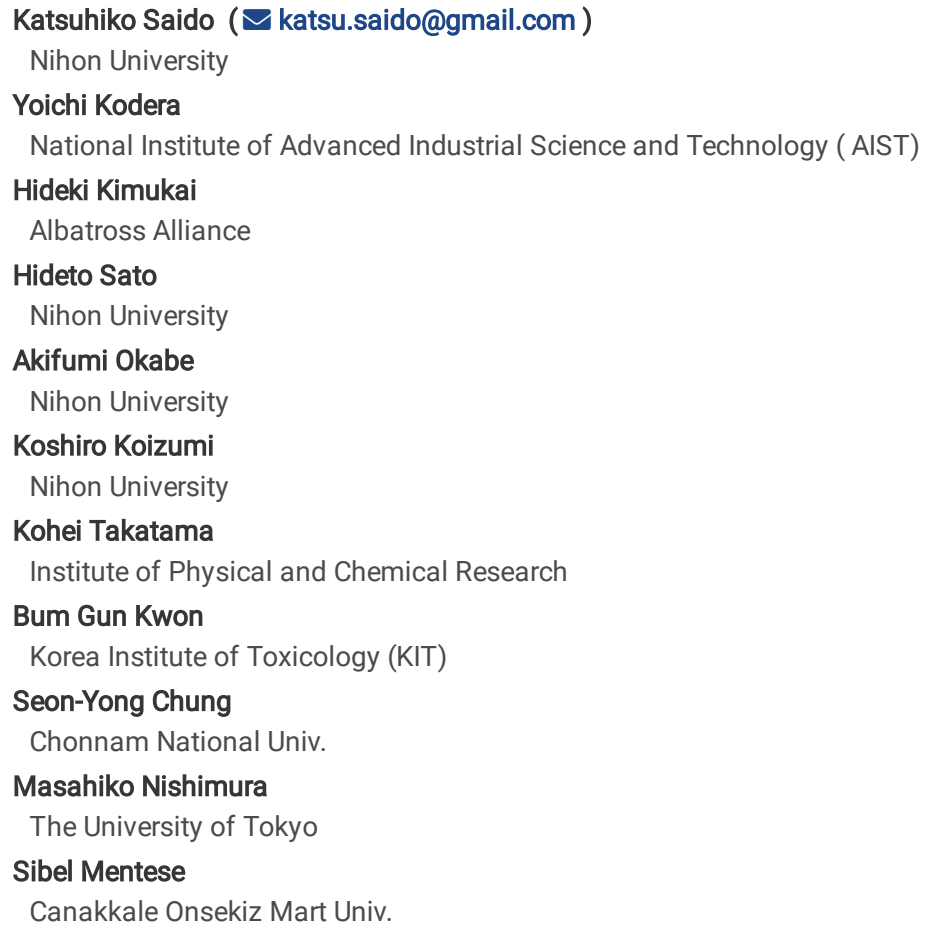




\section{Abstract}

Since 1970, lumps of plastic breakage into micro/nano pieces has been clearly shown a serious and large source of ocean pollution. To clarify in detail the course of this impact, thermoplastics were decomposed at natural conditions kinetically. And field surveys conducted on four thousand sand and water samples including these at deep-sea sites from around the world during the period, 2000 to 2015. All samples were found to contain styrene oligomers (SOs), that had been generated from drifting polystyrene (PS) degradation. Lumps of plastic not only break up into micro/nano-fragments but also degrade into their basic structure units of plastic. From 1950 to 2015, 4.2 billion metric tons (MT) of SOs were shown to be generated from drifting PS. The monomers are newly and highly significant source of pollution of marine ecosystem directly and global warming of planet and should be given the utmost serious attention.

\section{Introduction}

The cumulative amount of all plastics produced from 1950 to 2015 has been estimated at $7.8 \times 10^{9}$ metric tons (MT). ${ }^{1}$ Thermoplastics, polyethylene (PE), polypropylene (PP), polyvinyl chloride (PVC, including plasticized PVC) and polystyrene (PS) are the four major plastics produced in the greatest amounts, constituting for approximately $70 \%$ of total world production ${ }^{2}$. Whether accidentally or intentionally, waste PS from land sources ultimately makes its way into world oceans. PS has been shown a major constituent of drifting plastics and, due to its ability to float, is an outstanding factor contributing to world pollution.

Carpenter and Smith ${ }^{3}$ first reported plastic contamination in the western Sargasso Sea and indicated 3,500 floating pieces to have a weight of $290 \mathrm{~g} \mathrm{~km}{ }^{2}$. van Sebille $^{4}$, Eriksen ${ }^{5}$ and Cozar ${ }^{6}$ et al. calculated that between $7.0 \times 10^{3}$ to $2.7 \times 10^{5} \mathrm{MT}$ debris plastics to be present on ocean surfaces and to be the predominant constituent of "garbage patches" found throughout world ocean. ${ }^{7}$ By 2050 , debris plastics in oceans may possibly attain an exceeding that of all fish. ${ }^{8}$

Drifting lump plastics in oceans have been studied in great detail with major quite emphasis on plastic breakage into progressively smaller pieces (These pieces are visual to the naked eye. Chemically, they have the structures of macromolecules). To address this most serious problem of global waste plastic pollution, it is most urgent to make quantitative determination of waste plastic presently in world oceans, as well as their amounts afloat and the extent of their degradation. This undertaking should be possible by conducting the following steps:

[1]. Determination of amounts of plastic waste flowing into oceans.

[2]. Determination of amounts of plastic drifting on ocean surface.

[3]. The quantification of monomers, produced by plastic degradation, which

subsequently sedimentate on the ocean floor ${ }^{9}$. Differences in amounts of [1] within a given period [3] should serve as indication of drifting PS [2].

To clarify the amounts of degraded PS [3] in oceans, purified PS was decomposed within a natural temperature range kinetically and SOs were found to be the main products. ${ }^{10}$ Unlike PS, this product has been shown to dissolve in the ocean (Supplementary Information Section I). Over 4,000 sand and water samples from coastlines in 26 different countries and isolated islands as well as open oceans, including those taken from a depth of 5,000 m, were used to determine the amounts of SOs. SOs which had been found in all samples. ${ }^{11-14}$

\section{Results And Discussion}

\section{Worldwide SOs contamination}

The amount of waste PS inflow in oceans from 1950 to 2015 has been estimated as $1.5 \times 10^{7} \mathrm{MT}$, based on the assumption PS constitutes $7 \%$ total global plastic production $\left(4.8 \times 10^{8} \mathrm{MT}\right)^{2}$ and that $3 \%$ of this plastic flow into the world's oceans ${ }^{15}$ (Supplementary Information Section I, II). Various chemicals from Waikiki beach sand 1975 (Oahu island, USA) and Showa Base pebble 1984 (Antarctica base in Japan) typically found in phthalate (PAE), bisphenol-A (BPA) and SOs (mixture of styrene monomer: SM, 2,4-diphenyl-1-butene:styrene dimer, SD and 2,4,6-triphenyl-1-hexene:styrene trimer, ST) were detected. ${ }^{10}$ SM has been shown a breakdown product formed by cinnamon mold flora and possibly may be present in oceans as a single contaminant. ${ }^{16}$ But SOs with constant composition ratio (purified PS decomposition, SM1: SD1: ST5 and field survey in this study, SM1: SD1: ST8) is not naturally present in ocean. It is clear that SO contamination has been around for 45 years before. ${ }^{10}$

SO contaminants have been shown present in commercial PS products such as disposable lunch boxes, food trays, and noodle containers sold around the world.

The SO composition ratio was computed as SM1: SD1: ST11 (Extended Data sTable 1).

The exudation of SOs from these PS products enters rivers and oceans as contaminates. The degree of these SOs should be determined. ${ }^{10,17}$

Using $2.5 \mathrm{~L}$ water and $5.0 \mathrm{~g}$ sand dichloromethane extracts, SOs were analyzed in detail by Gas Chromatograph equipped with Mass Spectrometry $(\mathrm{GC} / \mathrm{MS}){ }^{10-14}$

Mean SO value from coastal surveys worldwide were found to be $1613.4 \mu \mathrm{g} \mathrm{kg}^{-1}$ for sand samples and $2.7 \mu \mathrm{g} \mathrm{L}^{-1}$ for water samples. SO contamination of sand was 600 times higher than that of water. All sampling sites are shown in Fig.1-A and SO analytical results in Extended Data sTable 2. The composition 
SM1: SD1: ST8 in water and sand samples, respectively.

The highest regional values of SOs in sand samples were for Greece (N:37098', 31,400 $\mu \mathrm{g} \mathrm{kg}^{-1}$, Extended Data sTable 2, site 9) and water for Washington/USA were ( $\mathrm{N}: 47^{\circ} 39^{\prime}, 30.4 \mu \mathrm{g} \mathrm{L}^{-1}$, Extended Data sTable 2, site 21-2). The area with the lowest So levels was in the Hawaii Islands/USA ( $\mathrm{N}: 21^{\circ} 18,24^{\prime}, 16.0 \mu \mathrm{g} \mathrm{kg}{ }^{-1}$ in sand and $0.02 \mu \mathrm{g} \mathrm{L}^{-1}$ in water, Extended Data sTable 2, site 21-k). Comparing the SO values of the world oceans, the sand is greatest in the Indian Ocean (Fig.1-A, site-12,13,14; 7,500 $\mu \mathrm{g} \mathrm{kg}^{-1}$ ), followed by the Atlantic Ocean (Fig.1-A, site-1,2,3,21-e,f,g,h,I and 24 east; $4,485 \mu \mathrm{kg} \mathrm{kg}^{-1}$ ) and the Pacific Ocean (Fig.1-A, site-15,16,17,18,19,20 21-a,b,c,d,k and 24 west; $650 \mu \mathrm{g} \mathrm{kg}^{-1}$ ). In water SO has been shown to be 4.0 to $6.0 \mu \mathrm{g} \mathrm{L}^{-1}$. Mediterranean SO (Fig.1-A, site$4,5,6,7,8,9,10,11) 5,375 \mathrm{~kg}^{-1}$ for sand and $2.6 \mu \mathrm{g} \mathrm{L}^{-1}$ for water. SO accumulation was observed on beach sand in an isolated sea.

SO amounts in the Northern Hemisphere were relatively small at high latitude where land and water surface temperatures were low, such as in Ullapool (United Kingdom, 57.89'N, Extended Data sTable 2, site 1), Sand point, Dutch Harbor and Anchorage (Alaska/USA, 55.20'N, 53.53'N, 61.13'N, Extended Data sTable 2, site 21-a both), but in large amounts at low latitude such as in Matara (Sri Lanka, 5.55'N, Extended Data sTable 2, site 13), Port Dickson (Malaysia, 2.32' N, Extended Data sTable 2, site 14 ), Limon and Puerto Soley (Costa Rica East side, 9.98'N, West side, 9.93'N, Extended Data sTable 2, site 24 both) (Fig.1-A). Beach sand is exposed directly to sunrays and so consequently surface temperatures of shallow coastal areas may reach as high as $60{ }^{\circ} \mathrm{C}$ during the day in tropical and subtropical areas, causing greater PS degradation. ${ }^{17}$ High SO values were found along coastlines near large cities such as London, Tokyo, Los Angeles, and Boston, all with high human population densities. A comparison of SO levels on the East coast (Extended Data sTable 2, sites 21-b, c, d, Pacific Ocean; coast line, 2,000 km) and West coast (Extended Data sTable 2, sites 21-e, f, g, Atlantic Ocean; coast line, 2,000 km) at the same latitude in USA, indicated East coast of levels to be 5 times as much in sand samples but 0.5 times as much in water samples compared to those on West coast. The 1.5 times high SO values on the west coast in water samples may possibly have been due to the high amounts of drift plastic from Asia while the high values for sand on the east coast, possibly due to high population density.

In the case of isolated islands such as São Miguel (Portugal, 37.48'N, Extended Data sTable 2, site 3), Hamilton (Bermuda, 32.30'N, Extended Data sTable 2, site 25) and Pohnpei (Micronesia, 6.92'N, Extended Data sTable 2-2, site 23) and Hawaii Islands (Kauai, Oahu, Molokai, Maui and Hawii) /USA, SO values low and possibly due only to PS debris (All sites in Fig. 1-A).

\section{Dispersion in the Northwest Pacific Ocean from Japan}

SO contamination along the shores of Japan and dispersion in the Northwest Pacific Ocean have been examined in great detail. The Japanese Ministry of Agriculture has divided the country into 9 areas for management. From these 9 designated areas, some 2,000 sand and water samples were analyzed during 2000 to 2015 . The means SO value in sand was $591.0 \mu \mathrm{g} \mathrm{kg}^{-1}$ and amount in water $1.3 \mu \mathrm{g} \mathrm{L}^{-1}$. Japanese SO values were almost the half in water, but the sand was $36 \%$ of world SO contamination. The details for these determinations are presented in another paper. ${ }^{14}$ Every year, 10,000 MT of drifting PS washed up onto the shore of Japan. ${ }^{18}$ SO contamination in sand may possibly arise from this.

Using Japanese Government and the University of Tokyo joint operation ocean research ship Hakuho-maru along a $160^{\circ}$ east longitude, 5,000 km north to south and 2,000 km east to west while making a HK-12-3 cruise during 2012 in the Northwest Pacific Ocean. SO contaminations were examined with $10 \mathrm{~L}$ were collected using

a Niskin-type water sampler at fixed depth from the bottom to surface. (Fig.1-A, red line, Table 1 and Extended Data sTable 3, Stn 1-18). In the open ocean, the SO composition ratio was SM1: SD3: ST26 at the surface (Extended Data sTable 3) and SM1: SD39: ST204 as the average value for data at the depths of $2,000,3,000$ and 4,000 $\mathrm{m}$ deep (Table 1). From these values, it is evident that ST is the major pathway for the formation from PS in the ocean. ${ }^{10}$ At sampling station (Stn)-9 and -8 showed SO contaminations two times and five times the values noted at the surface (Extended Data sTable 3). The size of the area examined was basically the same as that of the Northwest Pacific Garbage Patch (PGP, Fig 1-C). The surface current was 0.7 knots and the average salinity was 34.4 permil during the cruise (Extended Data sTable 3 ). On the other hand, the average salinity above a depth of 2,000 $\mathrm{m}$ is 37.0 permil and buoyancy is considered to increase (Table 1). SO was high (ca. $0.2 \mu \mathrm{L}^{-1}$ ) in the photic zone near the depth of $200 \mathrm{~m}$ (Fig.1-B), and the means SO value being about $0.1 \mu \mathrm{g}$ $\mathrm{L}^{-1}$ in the deeper than $2,000 \mathrm{~m}$ where there was no horizontal movement. This deep SOs may thus possibly adhere to or be adsorbed by organic or inorganic matter. This may perhaps be the reason for the vertical SO movement.

With consideration to various marine factors along Japanese coasts, determination was made of SOs dispersion in the open ocean as shown at Fig.1-C (Supplemental Information Section III) ${ }^{19}$. SOs were clearly shown to disperse from the coasts of Japan into the Northwest Pacific Ocean over time, to eventually accumulate at high concentrations in the PGP, as noted also for ordinary plastic debris. SOs from the open ocean were also detected in the Northwest Pacific Ocean at about $0.2 \mu \mathrm{g} \mathrm{L}^{-1}$ at the surface. At depths of 2,000 to 5,000m the SO value was 0.1 $\mathrm{\mu g} \mathrm{L}^{-1}$ at Table 1 and Fig.1-B.

\section{Estimated inflow, degradation and current drift}

Moore et $\mathrm{al}^{20}$ reported that a mean value of 334,271 floating pieces with a weight of $5,114 \mathrm{~g} \mathrm{~km}^{2}$ in the North Pacific Ocean surface. The amount of drifting plastic has increased 17 times by weight and the number of pieces to 95 times as much during the period 1972 to 2001 . Jambeck et al. ${ }^{15}$ estimated total waste plastics inflow in 2010 into world oceans to range from 4.8 to $12.7 \times 10^{6} \mathrm{MT}$. The use of satellite and garbage collection nets to quantify drifting plastics have not been proven entirely satisfactory.

In all these computations, ${ }^{4-6,8,15,21}$ there has always been considerable margin for error. There is really no completely relivable information on the quantities of plastics that have undergone degradation and sedimented to the ocean floor. 
Based on SO-free PS decomposition, one MT of purified PS was found to degrade at a rate of $0.3 \mathrm{~g}$ per year at $30^{\circ} \mathrm{C}$, at an activation energy of $42.0 \mathrm{~kJ} \mathrm{~mol}^{-}$ 110,17

The careful decomposition of other thermoplastics at natural temperature range kinetically are generate into monomers at low activation energy (Extended Data sTable 4): the heat resistant plastics PC and EPX 22 generate BPA, PET and PVC generate PAE and polyurethane (PU) generate diisocyanate. The toxicity of these monomers is endocrine ${ }^{23}$, teratogenic- ${ }^{24}$ and reproductive ${ }^{23,24}$ affects and potentially mutagen or carcinogenic ${ }^{24,25,26}$ is well known (Extended Data sTable 4).

Plastic/macromolecules do not metabolize though their monomers can be metabolized by living organisms. The activation energy for these thermoplastics were basically the same as for PS (Extended Data sTable 4). In actual situations, ST gradually degrades to give SM as well as SD, which degrades into SM. 10,17 We have been searching for SD and ST degrading bacteria from natural sources for over 20 years, but which still have not been isolated. Simulation results at PS degradation at $30^{\circ} \mathrm{C}$ indicated the total amount of degraded PS in oceans will come to 90 MT by 2015 ( $t=65$ year), this amount in excess of 400 MT by 2050 ( $\mathrm{t}=100$ year $).^{10}$

On the other hand, the amounts of drifting PS [2] are estimated based on SOs surveys [3] and inflow [1] into oceans throughout the world. Using total ocean water volume of $1.4 \times 10^{21} \mathrm{~L}$ and SO values of 0.1 and $0.2 \mu \mathrm{g} \mathrm{L}^{-1}$, which possibly may reflect the amounts of SO sedimentation (deep sea) and drift (surface), 4.2 billion MT of SO were shown present in ocean water columns between 1950 to 2015 (Supplemental Information Section II). This quantity of SOs was subsequently converted to the amount of PS as $2.6 \times 10^{6} \mathrm{MT}$ (Supplemental Information Section II).

It was estimated $1.5 \times 10^{7} \mathrm{MT}$ [1] of all PS production flows into the ocean ${ }^{1,15}, 2.6 \times 10^{6}$ of drift PS [3] was degraded and $1.2 \times 10^{7}$ MT PS [2] currently drifting. Drift plastic and generated monomer have both shown to be a significant source of serious threat throughout the entire global planet.

The ICPP reports that the amount of GHG increased by an average of 9\% every year from 2000 to 2017 and 2017 GHG reached 600 million MT per year 27 . PE and PP have been shown seven times that of PS production ${ }^{1}$, suggesting that drifting PE and PP may produce seven times or much more GHG than SO ${ }^{28,29}$. It was suggested that generation of GHG from drift PE, PP degradation should thus be considered a serious threat throughout the entire global planet.

Drift lump PS and particles tend to sink and undergo property change over time due to weathering, embrittlement, fragmentation and corrosion ${ }^{30,31}$. As shown by worldwide SOs contamination (Extended Data sTable 2), there are significant effects on the generation of SOs by geographical factors such as latitude, weather, wave, current, temperature, sun ray, population and so on ${ }^{14,15,17}$. Although the amount of PS degradation at $30^{\circ} \mathrm{C}$ and surveyed $\mathrm{SO}$ values are significantly different, the plastic degradation was shown to be promoted more in natural environments.

\section{Conclusions}

Thermoplastics do not remain permanently intact in the ocean with time degrade into monomers. New invisible monomer contamination is progressing in the world's oceans. Drift plastic and generated monomer have both shown to be a most serious threat not only to the marine ecosystem directly but to the global planet as a whole.

\section{Tables}

Table1 Deep sea SO values (ng $\mathrm{L}^{-1}$ ) and composition during HK12-3 cruising

\begin{tabular}{|c|c|c|c|c|c|c|c|c|c|c|c|c|c|}
\hline \multirow[t]{2}{*}{ Sampling Site } & \multicolumn{4}{|c|}{ Depth $2000 \mathrm{~m}$} & \multicolumn{4}{|c|}{$3,000 \mathrm{~m}$} & \multicolumn{4}{|c|}{$4,000 \mathrm{~m}$} & \multirow{2}{*}{$\begin{array}{l}\text { Salinity } \\
\text { permil }\end{array}$} \\
\hline & SM & SD & ST & SO & SM & SD & ST & so & SM & SD & ST & SO & \\
\hline Stn-1 & 0.4 & 26.2 & 133.6 & 160.2 & 1.3 & 9.0 & 126.2 & 136.5 & 1.1 & 29.3 & 26.7 & 57.1 & 37.8 \\
\hline Stn-5 & 0.3 & 4.1 & 141.7 & 146.1 & 0.3 & 13.1 & 118.2 & 131.6 & 0.3 & 23.4 & 124.6 & 148.0 & 37.3 \\
\hline Stn-9 & 0.6 & 17.6 & 154.5 & 172.7 & 0.3 & 34.3 & 144.9 & 179.5 & 0.5 & 18.5 & 158.4 & 177.4 & 36.4 \\
\hline Stn-12 & 0.2 & 24.2 & 104.5 & 128.9 & 0.3 & 3.6 & 120.3 & 124.2 & 0.2 & 6.7 & 87.1 & 94.0 & 37.1 \\
\hline Stn-15 & 0.4 & 13.2 & 97.9 & 111.5 & 0.9 & 16.7 & 114.6 & 132.2 & 1.1 & 5.1 & 110.5 & 116.7 & 36.7 \\
\hline Stn-16 & 0.1 & 53.8 & 38.8 & 92.7 & 0.5 & 30.2 & 26.6 & 57.3 & 0.2 & 18.6 & 11.2 & 30.0 & 36.7 \\
\hline Sub Total 6 & 2 & 139.1 & 671 & 812.1 & 3.6 & 107 & 650.8 & 761.3 & 3.4 & 101.6 & 518.5 & 623.2 & 222 \\
\hline Average & 0.33 & 23.18 & 111.83 & 135.35 & 0.6 & 17.8 & 108.5 & 126.9 & 0.57 & 16.93 & 86.42 & 103.9 & 37 \\
\hline \multicolumn{14}{|c|}{$\begin{array}{l}\text { Composition Ratio } \\
\text { each depth }\end{array}$} \\
\hline SM:SD:ST & 1 & 70 & 339 & & 1 & 30 & 181 & & 1 & 30 & 153 & & \\
\hline Total SO & SM:9 & SD:347.6 & ST:1840 & & & & & & & & & & \\
\hline SM:SD:ST & 1 & 39 & 204 & & & & & & & & & & \\
\hline
\end{tabular}

Stn: Sampling station

\section{References}

1.Geyer R., Jambeck J.R., Law K.L., Production, use, and fate of all plastics ever made, Sci.Adv.2017;3:e1700782 
2.Plastics Europe, "The compelling facts about plastics: An analysis of plastic production, demand and recovery for 2006 in Europe" (Plastics Europe, 2008; https://www.plasticseurope.org/application/files/2815/1689/9283/2006compelling_fact_PubJan2008.pdf )

3.Carpenter E.D., Smith K.L. Jr., Plastics on the Sargasso Sea surface. Science 175, 1240-1241 (1972).

4.van Sebille E., Wilcox C., Lebreton L., Maximenko N., Hardesty B.D., Franeker J.A., Eriksen M., Siegel D.,Galgani F., Law K.L., A global inventory of small floating plastic debris. Environ. Res. Lett.10 doi: 10.1088/1748-9326/10/12/124006 2015 (2015).

5.Eriksen M.L., Lebereton C.M., Carson H.S., Thiel M., Moore C.J., Borerro C.J., Galgani F., Ryan P.G., Reisser J., Plastic pollution in the world's oceans: more than 5 trillion plastic pieces weighing over 250,000 tons afloat at sea. PLOS ONE doi:10.1371/journal.pone.0111913 2014 (2014).

6.Cozar A., Echevarria F., Gonzalez-Gordillo J.I., Irigoien X., Ubeda B., Hernandez-Leon S., Palma A.T., Navarro S., Garcia-de-Lomas J., Ruiz A., Fernandez-dePuelles M.L., Duarte C.M., Plastic debris in the open ocean. PNAS, 111(28) 10239-10244 doi:10.1073/pnas.1314705111 2014 (2014).

7.Lebreton L., Slat B., Ferrari F., Sainte-Rose B., Aitken J., Marthouse R., Hajbane S., Cunsolo S., Schwarz A., Levivier A., Noble K., Debeljak P., Maral H., Shoeneich-Argent R., Brambini R., Reisser J. Evidence that the great Pacific garbage patch is rapidly accumulating plastic. Nature Sci. Rep. 8, 4666 (2018).

8.Jennings S., Melin F., Blanchard J.L., Forster R.M., Dulvy N.K., Wilson R.W., Global-scale predictions of community and ecosystem properties from simple ecological theory (Proceedings of the Royal Society B, 2008)

https://doi.org/10.1098/rspb.2008.0192

9.Martin J., Lusher A., Thompson,R.C., Morley A., The deposition and accumulation of microplastics in marine sediments and bottom water from the Irish continental shelf 2017;7:10772|DOI:10.1038/s41598-017-11079-2.

10.Kimukai H., Kodera Y., Koizumi K., Okada M., Yamada K., Hiaki T., Saido K., Low temperature decomposition of polystyrene, Appl.Sci., 2020, 10,5100; doi:10.3390/app10155100

11.Saido K., Koizumi K., Sato H., Ogawa N., Kwon B.G., Chung S.-Y., Kusui T., Nishimura M., Kodera Y., New analytical method for the determination of styrene oligomers formed from polystyrene decomposition and its application at the coastlines of North-West Pacific Ocean. Sci. Total Environ. 473-474, 490-495 (2014).

12.Kwon B.G., Amamiya K., Sato H., Chung S-Y., Kodera Y., Kim S-K., Lee E. J., Saido K., Monitoring of styrene oligomer as indicator of polystyrene plastic pollution in the North-West Pacific Ocean. Chemosphere, 180, 500-505 (2017).

13.Amamiya K., Saido K., Chung S-Y., Hiaki T., Lee D.S., Kwon B-G.. Evidence of transport of styrene oligomers originated from polystyrene plastic to oceans by runoff. Sci. Total Environ., 667, 57-63 (2019).

14.Amamiya K., Koizumi K., Yamada K., Hiaki T., Kusui T., Saido K.. Analysis of Drifting Polystyrene Degradation Surround Japan, Austin J. Environ.Txicol.,6, id1030 (2020).

15.Jambeck J.R., Geyer R., Wilcox C., Siegler T. R., Perryman M., Andrady A., Narayan R., Law K. L., Plastic waste inputs from land into the ocean. Science 347, 768-771 (2015). doi:10.1126/science.1260352

16.Lafeuille J-L., Buniak M-L., Vioujas M-C., Lefevre S., Natural formation of styrene by cinnamon mold flora. J. Food Sci. 74, 276-283 (2009).

17.Saido K., Taguchi H., Kodera Y., Ishihara Y., Ryu I-J., Chung S-Y., Novel method for polystyrene reactions at low temperature. Macromol. Res. 11, 87-91 (2003).

18."2014 Research report on marine debris floating on the ocean surface and settled on the sea bed in offshore areas around Japan (summary)," Ministry of the Environment, 2015;

<http://www.npec.or.jp/NWPacific_node/report/document/2014Research_report_on_marine_debris_floating_on_the_ocean_surface_around_Japan\%20(revised (September 2019).

19.Bonjean F., Lagerloef G.S.E., Diagnostic model and analysis of the surface current in the tropical Pacific Ocean. J.Phys. Oceanogr., 32, 2938- 2954 (2002).

20.Moore C.J., Moore S.L., Leecaster M.K., Weisberg S.B., A comparison of plastic and plankton in the north pacific central gyre. Marine Poll. Bull., 42, 12971300 (2001).

21.Isobe A., Iwasaki S., Uchida K., Tokai T., Abundance of non-conservative microplastics in the upper ocean from 1957 to 2066. Nature commun. (2019) 10:417 doi:10.1038/s41467-019-08316-9 2019

22.Saido K., Kodera Y.,Kuroki T., Park J-H., Chung S-Y., Low temperature

decomposition of epoxy resin, Macromol. Res., 22, 490-492 (2004). 
23.Preethi S., Sandhya K., Lebonah D. E., Prasad Ch. Venkata, Sreedevi B., Chandrasekhar K., Kumari J. P., Toxicity of bisphenol A on humans. Intern. Lettr. Natul Sci., Online: 2014-10-15 ISSN: 2300-9675, 27, 32-46 doi:10.18052/www.scipress.com /ILNS.27.32 2014

24.Dillingham E. 0., Autian J., Teratogenicity, Mutagenicity, and Cellular Toxicity of Phthalate Esters Environ. Health Persp., 3, 81-89 (1973).

25.Leibman K.C., Metabolism and Toxicity of Styrene. Environ. Health Persp., 11,115-119 (1975).

26.Pauluhn J., Inhalation Toxicity of 1,6-Hexamethylene Diisocyanate Homopolymer (HDI-IC) Aerosol: Results of Single Inhalation Exposure Studies, Toxicol. Sci., 58, 173-181 (2000., https://doi.org/10.1093/toxsci/58.1.173

27. 27. Saunois et al., The global methane budget 2000-2017.Earth Syst.Sci. Data., 12,1561-1623 (2020). https:// doi.olg/10.5194/essd-12-1561-2020

28. Royer S-J., Ferron S., Wilson S.T., Karl D.M., Production of methane and ethylene from plastic in the environment 2018 https://doi.org/10.1371/journal.pone.0200574

29. Zheng J., Suh S., Strategies to reduce the global carbon footprint of plastics, Nat. Clim. Chang, 9, 374-379 (2019). http://doi.org/10.1038/s41558-0190459-z

30.Kukulka T., Proskurowski G., Ferguson S. Morét, Meyer D.W., Law K.L.,

The effect of wind mixing on the vertical distribution of buoyant plastic debris. Geophys. Res. Lett., 39, L07601 (2012).

31.Bianco A., Sordello F., Ehn M., Vione D., Passanati M., Degradation of nanoplastics in the environment: Reactivity and impact on atmospheric and surface waters. Sci. Total Environ.,742 (2020) 140413, doi.org/10.1016/j.scitotenv.2020.140413.

32.Murphy J., Additives for Plastics Handbook (Elsevier, ed. 2, 2011).

33.Staudinger H., Steinhofer A., Über hochpolymere Verbindungen. 107. Beiträge zur Kenntnis der Polystyrole. Ann., 517, 35-53 (1935).

34.Madorsky S.L., Rate of thermal degradation of polystyrene and polyethylene in a vacuum. J. Polym. Sci., 9, 133-156 (1952).

\section{Declarations}

\section{Acknowledgments:}

The authors gratefully acknowledge Hiratsuka R., Suzuki Y., Taguchi H., Metori K., Kusui T., Abe O., Kojima A., Yamaguch M., Miyashita K., (Japan), Okazaki H., Odegard B. K., Otsuka T. (U.S.A.) for their valuable assistance.

We also thank Prof. Kogure K., Prof. Tsuda A., and Prof. Ogawa H., at Atmosphere Ocean Research Institute, the University of Tokyo, for their valuable instructions. The captains, Suzuki S., Fujita U. and Seino N., who gave much encouragement during the voyage, are greatly appreciated. The crews of Hakuhomaru and Tansei-maru of the Japan Agency for Marine-Earth Science and Technology are thanked very much for their kind hospitality.

Funding: We made use of the regular budgets from the respective institutions at which the authors work, as well as personal expenses on behalf of the authors.

\section{Author contributions:}

This paper is dedicated to UIC Emeritus Distinguished Professor Ananda Mohan Chakrabarty, who died $10^{\text {th }}$ July 2020.

S.K. contributed the total coordination of this project, degradation, field survey and analysis. K.Y. contributed the kinetic calculation of PS decomposition.

T.K.contributed the SO dispersion into ocean. B-G.K., S-Y.C., A.C. are the isolation and biochemical analysis of SO-degrading bacteria. K. H., S.H., O.A., K. K., T.K., N.M. and M.S. contributed field sampling and discussions.

Competing interests: The authors declare no competing interests.

Data and materials availability: All data is available in the main text, the extended data figures and tables, or the supplementary information.

Fig. 1 -A, B, C and Table 1

Extended data figures and table

Extended Data sTables $1-4$

Supplementary information: Sections I, II, III

References (1-34)

\section{Figures}


a
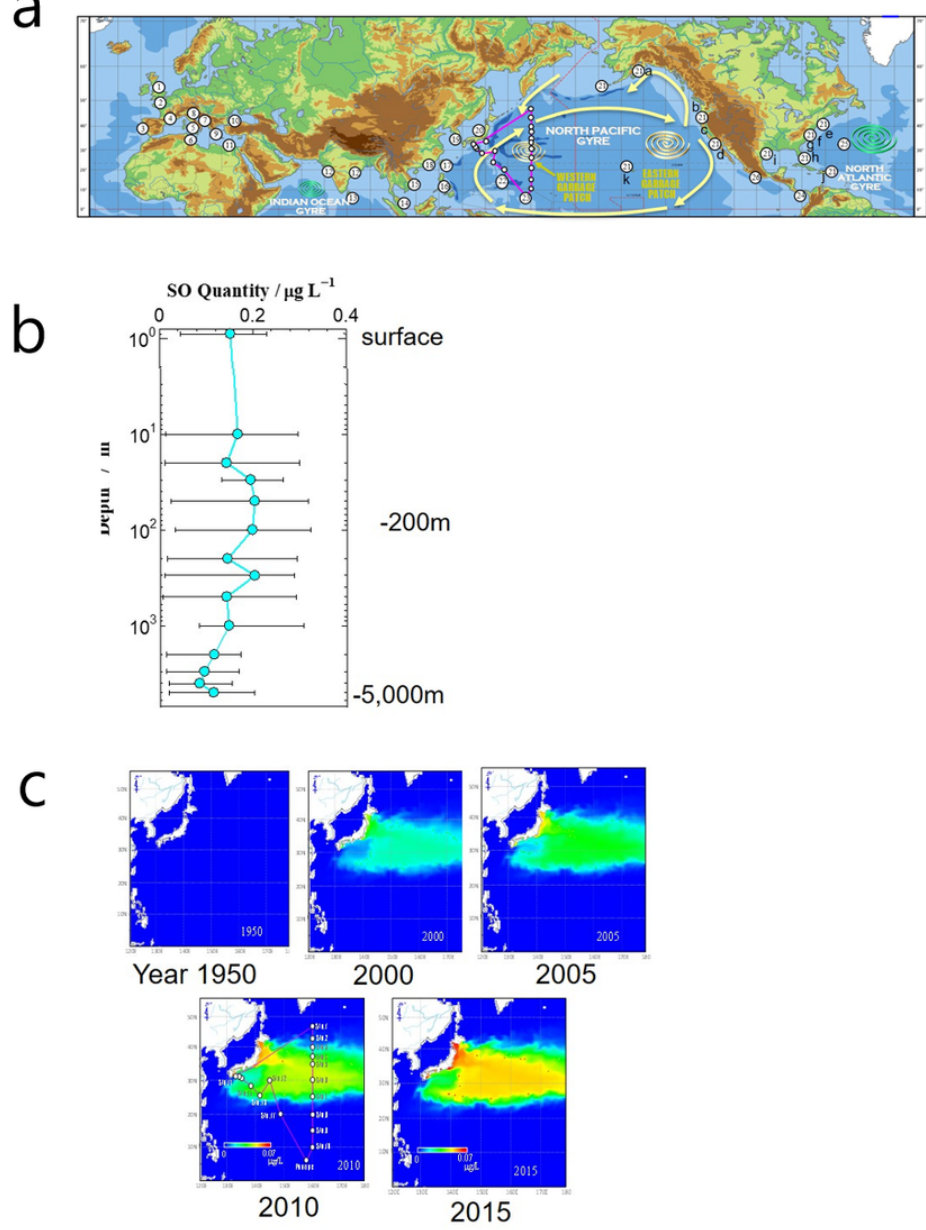

Figure 1

A Map of sampling sites and cruise stations. Typical sampling sites 1 through 26 (number in a circle) are on beaches in coastal areas. The circles along red line are sampling stations (Stn) during open ocean sampling (cruise number: HK12-3, Stn 1-18). Yellow arrows designate the major ocean currents in the North Pacific Ocean. Main ocean garbage patches are shown with cycles (yellow and green) in the North Hemisphere. B Vertical SOs value. Distributions of SOs surface to $5,000 \mathrm{~m}$ depth during cruise (HK12-3, 6th July to 14 thAugust 2012 ) in the open ocean $\left(10^{\circ}\right.$ to $45^{\circ} \mathrm{N}, 133^{\circ}$ to $\left.160^{\circ} \mathrm{E}\right)$. note: 1 . photic zone, turbulent mixing to $1,000 \mathrm{~m} 2$. The water depth on the left axis is shown in a log scale C Simulated dispersion of SOs ( $\mu$ g L-1) into Northwest Pacific Ocean originating from Japan (1950 - 2050). (X-Y axes show the coordinates). Note: The designations employed and the presentation of the material on this map do not imply the expression of any opinion whatsoever on the part of Research Square concerning the legal status of any country, territory, city or area or of its authorities, or concerning the delimitation of its frontiers or boundaries. This map has been provided by the authors.

\section{Supplementary Files}

This is a list of supplementary files associated with this preprint. Click to download.

- SupplementaryFile.docx 